\title{
Comunidades ribeirinhas na Amazônia: perdidas no espaço e no tempo dos grandes projetos hidrelétricos
}

\section{Riverside communities in Amazon: lost in space and time of mega-dams}

\section{Luis Fernando Novoa Garzon}

Brasil. Universidade Federal de Rondônia. Professor da Universidade Federal de Rondônia (Unir) lotado no Departamento de Ciências Sociais. Formação na área de Ciência Política, Doutor em Planejamento Urbano e Regional pelo Instituto de Pesquisa em Planejamento Urbano e Regional da Universidade Federal do Rio de Janeiro (Ippur-UFRJ). Coordena o Grupo de Pesquisa "Territorialidades e Imaginários na Amazônia", na Unir, e é um dos coordenadores do Programa de Pesquisa "BNDES: Grupos Econômicos, Setor Público e Sociedade Civil no Contexto Nacional e Internacional”, vinculado ao Laboratório Ettern (Estado, Território, Trabalho e Natureza) do Ippur-UFRJ. ID ORCID: http:// orcid.org/0000-0003-2280-7959.E-mail:l.novoa@unir.br.Colaboração:pesquisa bibliográfica, análise de dados, redação e sistematização do artigo.

\section{Daniele Severo da Silva}

Brasil. Secretaria de Estado da Educação de Rondônia e Universidade Federal de Rondônia. Graduação em Ciências Sociais pela Universidade Federal de Rondônia (2013). Especialização em Sociologia e Ensino de Sociologia pelo Centro Universitário Claretiano (2016). Atua como professora de Sociologia do Estado de Rondônia. Pesquisadora no grupo de pesquisa Territorialidades e Imaginários na Amazônia, da Universidade Federal de Rondônia (Unir). ID ORCID: https://orcid. org/0000-0002-8922-0039. E-mail: danielessevero@gmail.com. Colaboração: pesquisa empírica, leitura, análise de dados, redação e sistematização do artigo.

\section{Resumo}

O texto demonstra, a partir da implementação das Usinas Hidrelétricas Santo Antônio e Jirau no rio Madeira (Rondônia, Brasil), os caminhos institucionais e discursivos específicos adotados na expansão dessa fronteira, que precificam e nivelam por baixo padrões de proteção ambiental e de direitos sociais e culturais vigentes no país. Verificamos como se enredaram esses processos em pesquisa e diálogo com os moradores da comunidade Maravilha. Nesse contato percebemos que, apesar das sucessivas desterritorializações impostas à comunidade, prossegue 
a trama por sua sobrevivência econômica, social e cultural. Nosso objetivo foi definir os marcos dessa trama, contribuindo para a reflexão, valorização e proteção de âmbitos culturais realçados no envolvimento efetivo dos moradores na construção de suas narrativas e na singularização de seus lugares e patrimônios.

Palavras-chave: Comunidades Ribeirinhas Amazônicas, Desterritorialização, Direitos Territoriais, Grandes Projetos Hidroelétricos, Valorização e Proteção de Âmbitos Culturais.

\section{Abstract}

This study analyzes the implementation of the Santo Antônio and Jirau Hydroelectric Power Plants on the Madeira River (Rondônia, Brazil) to determine the specific institutional and discursive trajectories adopted in the expansion of this border, which applies prices and undermine environmental protection standards as well as social and environmental rights in the country. We verified how these processes were involved in research and dialogue with the residents of the Maravilha community. During this contact we realize that despite the successive deterritorialization imposed on the community, its economic, social and cultural survival is still at stake. Our aim was to define the notorious moments of their situation, contributing to the reflection, valorization and protection of cultural areas emphasized by the effective involvement of the residents in the construction of their narratives and in the singularization of their places and patrimonies.

Keywords: Amazon Riverside Communities, Deterritorialization, Territorial Rights, Mega-dams, Valorization and Protection of Cultural Areas.

\section{INTRODUÇÃO}

O início dos grandes projetos na Amazônia, a partir de 2003, com destaque para grandes empreendimentos de energia elétrica, pode ser representado como um novo um ciclo de apropriação econômica e de expropriação social na região Amazônica. Destacaremos aspectos da territorialização empresarial 
promovida na região da bacia do rio Madeira, a partir da construção das Usinas Hidrelétricas (UHE) de Santo Antônio e Jirau ${ }^{1}$.

Fica evidente que a expropriação do rio e de seus usos sociais se vincula à expropriação da capacidade de percepção e inteligibilidade do território recriado. De pronto observemos, portanto, os resultados da privatização e tecnificação da dinâmica das águas, sedimentos e peixes do rio Madeira na última década. A montante dos dois reservatórios, dezenas de comunidades foram dissipadas e tragadas subitamente, enquanto outras foram sendo gradativamente inviabilizadas e ilhadas, à medida que águas, que antes corriam, estacionassem e se espraiassem. A jusante da UHE Santo Antônio, na chamada "Área de Influência Indireta”, de Porto Velho até o distrito de Calama, no estado de Rondônia, a limpeza social, ainda que mais lenta, não se fez menos notada.

Dentre essas comunidades marcadas ${ }^{2}$ pelo $\mathrm{X}$ do "progresso" trazido pelas Usinas e pela cheia histórica de 2014, encontra-se a comunidade Maravilha, uma das comunidades ribeirinhas remanescentes no entorno urbano de Porto Velho. $\mathrm{O} X$, indicador de remoção, simboliza também um alvo. Trata-se de mais uma contagem regressiva na Amazônia engatilhada por grandes projetos privados viabilizados com recursos públicos e frouxidão institucional. Essa foi a fórmula consensualmente adotada pelo setor elétrico e por agências governamentais, desde o primeiro governo Lula, para incorporar a região amazônica de forma integral aos circuitos operacionais dos oligopólios privados transnacionais.

O grupo Odebrecht, controlador da UHE Santo Antônio, e o grupo Suez, controlador da UHE Jirau, expressam, por meio dos seus consórcios público-privados, conexões diretas e particulares com instâncias estatais que, em tese, deveriam ter natureza pública e estratégica, como o Ministério de Minas e Energia, a

\footnotetext{
Territorialização que se consolida com a intensificação do rio Madeira como escoadouro de commodities produzidas em escala e homogeneidade proporcionais à devastação de biomas e territórios tradicionais neles adscritos.

2 Em 2014, a Defesa Civil do Estado de Rondônia procurou consignar o desastre induzido da grande cheia daquele mesmo ano, com a ampliação da área de risco nas margens do rio Madeira e a indicação de remoção de comunidades ribeirinhas centenárias por meio da grafia de um X vermelho em suas habitações. Conferir documentário sobre a controvérsia social e técnica acerca das causas da cheia histórica do rio Madeira. Disponível em: http://bit.ly/38rpJcz. Acesso em: 12 fev. 2020.
} 
Agência Nacional de Águas (ANA), a Agência Nacional de Energia Elétrica (Aneel) e o Banco Nacional de Desenvolvimento Econômico e Social (BNDES).

A genealogia do licenciamento ambiental e do processo de financiamento por parte do $\mathrm{BNDES}^{3}$ de cerca de $75 \%$ (em torno de $\mathrm{R} \$ 20$ bilhões) das duas usinas e suas linhas de transmissão demonstra exemplarmente como essa fórmula de comoditização do território foi implementada na bacia do rio Madeira. A comunidade Maravilha passou a ser afetada duramente logo após o fechamento das comportas em 2012. Um conjunto de desbarrancamentos nas duas margens do rio, quilômetros abaixo, inviabilizou as barrancas do rio Madeira como área de reprodução econômica, social e cultural das comunidades ribeirinhas. Ao mesmo tempo, intensificaram-se ações de incorporação dessas áreas por empresas que fornecem serviços de transporte e logística hidroviária (eixo Porto VelhoManaus), além da especulação imobiliária e da grilagem sobre as terras de posse tradicional, que ganhou corpo com a construção da ponte sobre o rio Madeira no fim de 2013.

Demonstrar como avançam as diversas frentes de despossessão na região é fazer que as políticas de desaparição social apareçam e sejam confrontadas. Sem perder de vista a necessidade de inquirir sentimentos e identificações que alimentam esse processo de extinção social: de um lado, a ostentação possessivista e a indiferença com o destino dos que foram vulnerabilizados; de outro, o colapso emocional dos continuadamente atingidos e a constante oscilação entre o pânico e a sensação de desintegração.

\section{APONTAMENTOS METODOLÓGICOS}

Assim, este artigo procurar registrar esse processo de esvaziamento espacial-temporal (GIDDENS, 1991) que pôde ser aferido na comunidade

\footnotetext{
Realizou-se consistente estudo sobre a política de financiamento do BNDES entre 2003 e 2014 pelo Laboratório ETTERN do IPPUR-UFRJ, em pesquisa coordenada por Carlos Vainer e Flávia Vieira (2017). Sobre o mesmo tema, conferir também o estudo de Novoa Garzon (2010).
} 
Maravilha, entre março e julho de 2018, por meio de observação direta, participação em reuniões e entrevistas com os moradores mais antigos. Trata-se de uma pesquisa exploratória que procura preparar o terreno e calibrar ferramentas analíticas para a realização de estudos de caso em comunidades ribeirinhas em condição similar de tensão desintegradora. Nossa metodologia buscou incorporar componentes etnográficos com realização de entrevistas em que se buscou registrar as múltiplas incidências e temporalidades de cada uma das interações (BARBOT, 2015).

A organização do sequenciamento de encontros em territórios desfigurados e em disputa precisa lidar com o imponderável e fazer dele chave de leitura para reprogramações e observações. Afunilamentos e desvios se repetiram ao longo da pesquisa: os entrevistados, ainda que evitando o momento formal do registro, mantiveram o mesmo nível de abertura para tratar do cotidiano do lugar perdido e deslocado. Depois de inúmeros cadastramentos, peritagens, medições, interdições em função dos impactos da UHE Santo Antônio e da grande cheia de 2014, cada entrevista trazia a sombra da armadilha.

Ainda que nos valêssemos de atalhos abertos por atividades de pesquisa e extensão anteriores, em conjunto com uma associação cultural local ${ }^{4}$, a cada solicitação de agendamento de conversa sempre ecoava na resposta, direta ou evasiva, a pergunta ainda mais inevitável nesse contexto (GEERTZ, 1997): que diabos querem saber ou o que pensam fazer com isso?

Como muitas famílias dão por certa a inviabilidade de continuar a viver na comunidade, considerando as drásticas descontinuidades a que foram submetidas, era possível compor uma escala do silenciamento a depender do tema e da abordagem. Nesses termos, o intento foi o de reconstituição das trajetórias dos moradores que primeiro chegaram e constituíram a comunidade, para em seguida procurar comparar e caracterizar a sobreposição de configurações sociais anteriores e posteriores à construção das hidrelétricas (SIGAUD, 1986).

Associação Cultural Arirambas. 


\section{AJUSTES ESPACIAIS EM ESCALA AMAZÔNICA}

A região amazônica tem servido de suporte e aprofundamento do "padrão de especialização produtiva" (OSÓRIO, 2012) notabilizado pelo uso intensivo de recursos naturais, pela flexibilização de direitos territoriais e de normativas ambientais, e pela precarização e desvalorização da força de trabalho. Não casualmente os setores considerados carros-chefe desse modelo - indústria extrativa mineral, agronegócio e infraestrutura - estão fortemente ancorados na Amazônia e seguem em contínua expansão. Quem vai pavimentando esse caminho são elites desenraizadas, empreendedoras de genocídios e ecocídios simultaneamente.

A Amazônia ganhou relevo na divisão inter-regional do trabalho a partir dos anos 1970 com a assunção de "funções agropecuárias" crescentes, na sequência da marcha para o (Centro-)Oeste. A consolidação das fronteiras agrícola, mineral e energética na Amazônia décadas depois expressa como se deu o processo de homogeneização do espaço econômico do país por garantia de otimização das taxas de lucro nas margens, nos espaços periféricos subalternizados (OLIVEIRA; REICHSTUL, 1973).

O Grande Projeto de Investimento (GPI), em geral, e o Hidrelétrico, em particular, são resultado expresso da confluência de estratégias desencadeadas a partir de distintas escalas e níveis de poder. Dependendo do poder multi e interescalar em um Grande Projeto, ficava retida sob sua jurisdição a política ambiental, a fundiária e, de quebra, a indígena. Suspensos os propósitos descolonizadores e preservados os privilégios de origem permanente, os empreendedores podem declarar a nulidade de territórios tradicionais. João Pacheco (1990, p. 31), por exemplo, antevia no Projeto Calha Norte uma força normatizadora intrínseca, considerando que sua atuação mantinha "um alto componente de escolha, escolhido em cada caso em função de um certo diagnóstico da situação e de uma constelação particular de alianças”.

O Grande Projeto como "enclave político", concluem Vainer e Araújo (1992, p. 49-50), é antitético a qualquer planejamento regional, e de resto fica a "região ex-post", o próprio habitat feito para e pelo negócio. A região se torna coerente com a exogenia dos atores envolvidos e com sua própria natureza 
insular mediante a região receptora. Esta passa de alvo de política a espaço para políticas de apropriação plena de seus recursos por meio de macropolíticas setoriais que reconfiguram o espaço nacional.

Se nos anos 1970 e 1980 grandes projetos hidrelétricos na região materializavam espaços socialmente segregados e jurisdições territoriais ad hoc, a partir dos anos 2000, passam a envolver um nível superior de articulação interescalar e uma maior pretensão homogeneizadora da regulação pró-mercados. Por isso é na Amazônia que se forja a forma-padrão de apropriação de recursos territorializados em larga escala, o modelo neoextrativista que condena a região a ser uma eterna sucessão de enclaves em rotação - um enorme menu territorial à disposição de investidores privados e suas encomendas. A sintetização da Amazônia (e das formas sociais conviviais que lhe singularizam) disponibiliza oportunidades para investidores em termos claramente dedutíveis: blocos de jazidas, áreas agricultáveis, potencial de geração de megawatts, créditos-carbono e respectivas mercadorias futuras (PORTO-GONÇALVES, 2018; SANTOS; SILVEIRA, 2004).

O redesenho da América do Sul planejado pela Iniciativa para a Integração da Infraestrutura Regional Sul-Americana (IIRSA) dependia da abertura de corredores de exportação de commodities, através da região amazônica, ou seja, através dos países em que está contida. A meta de “integração física”, objeto da iniciativa, pressupõe um patamar técnico desejável de conectividade econômica, como se a mobilidade dos capitais fosse regida de forma horizontal e multidirecional. Na verdade, os "eixos de integração" concebidos para realizar essa interconexão são antes eixos de concentração e de valorização que dão acesso a habilidades e rentabilidades territoriais de largo espectro. Os novos espaços de valorização vislumbrados - seja em programas governamentais pretéritos, como o Programa de Aceleração do Crescimento (PAC) e o Programa Integrado de Logística, seja em programas vigentes como o Parceria para Investimentos (PPI) - seguem a mesma regra de ouro: atrair investimentos por meio do rebaixamento dos custos e das regulamentações (NOVOA GARZON, 2017).

Novas parcerias entre capitais e reconfigurações passam a ser fundadas na garantia de dinamismos adicionais e extraordinários para a realização de valor. O que retoricamente se temia, a chamada "internacionalização da Amazônia", 
tornou-se agora uma premissa regulatória: prerrogativas máximas para os investimentos, sem distinção de origem. O que atrai de fato os investimentos estrangeiros, para além da aquisição e capitalização de blocos de recursos naturais, é a possibilidade de empresariar a gestão de extensas faixas territoriais. Estes são corredores previstos para operarem como zonas econômicas especiais voltadas para a extração e a circulação de commodities, na forma de concessões minerárias e de infraestrutura incondicionadas. Que tipo de desenvolvimento pode advir desse progresso ininterrupto da espoliação?

$\mathrm{O}$ quadro se agrava na conjuntura recente com o estabelecimento de processos de ruptura institucional e "mafialização"5 da representação política, a partir de 2016. Medidas congressuais-governamentais têm franqueado a exploração compulsória de recursos naturais na região, suspendendo-se a vigência de direitos territoriais reconhecidos nacional e internacionalmente.

A instrumentalização da Amazônia enquanto estoque de matérias-primas e plataforma logística para seu armazenamento e escoamento requereu devastações físicas e simbólicas de biomas e culturas entrelaçadas, de territorialidades de povos indígenas, de quilombolas, de camponeses extrativistas, pescadores e ribeirinhos. A própria concepção da Amazônia como reserva de riqueza se vincula a uma percepção "capitalistocêntrica” que nega qualquer alteridade sistêmica (SPIVAK, 2010). Nessa ótica autorreferente, pressupõe-se a existência de um nível econômico-tecnológico superior por puro mérito civilizador. Demérito, portanto, dos não abrangidos, dos "de fora", dos não prontamente assimiláveis às relações sociais apresentadas como "competitivas". Bloqueio e desqualificação daqueles mesmos olhares e vozes não engolfados pelo discurso técnico-científico, para que não haja controvérsias e desgaste acerca dos requisitos indispensáveis do crescimento econômico (ZHOURI; LASCHEFSKI; PEREIRA, 2014).

A chantagem é duplicada sobre os territórios que recepcionaram bolhas de crescimento das grandes obras. A desestruturação social e ambiental promovida pelos chamados projetos “estruturantes”, como o complexo hidrelétrico do

Utilizamos aqui o conceito de Rita Segato (2014) acerca da “duenidad", que supera a colonialidade para explicar formas de dominação integral dos territórios, com base em seus estudos das práticas das máfias mexicanas. 
rio Madeira (além de Santo Antônio e Jirau, conta com mais duas usinas projetadas: uma binacional e outra boliviana) prepara de fato novas estruturações e especialização espaciais e territoriais. A região, incorporada agora como província hidrelétrica, representa um marco superior de capitalização e despossessão não só pelo volume de recursos privatizados, mas pelo que franqueia em termos de novas disponibilizações territoriais a partir da prévia anulação de subjetividades coletivas formadas e recriadas ao longo desse grande rio amazônico.

\section{PRECARIZAÇÃO DOS CONTORNOS SOCIAIS E PORQUE SOMOS TODOS TAMBÉM RIBEIRINHOS}

O modelo rentista-neoextrativista (CARVALHO; MILANEZ; GUERRA, 2018), ao qual o país foi entregue nas últimas décadas, combina reiteradas expropriações primárias ao longo da fronteira econômica, com formas espoliativas de última geração. Conferindo-se absoluta discricionaridade privada às concessões minerárias, energéticas e dos setores de infraestrutura, não há mais eco de soberania possível. Com a permissão de multiplicação da dívida pública e o uso ilimitado de derivativos financeiros, com destaque para os mercados futuros de commodities, o país perde qualquer pretensão de definir contornos sociais, implodidos os regimes de convivência e direitos territoriais decorrentes.

O rio Madeira é alçado à condição de plataforma elétrica e, depois, de plataforma logística enquanto todos que dele ou nele viviam desaparecem como sujeitos, como titulares de territórios e de direitos. Quem considera tolerável apagar modos de vida singulares para que existam corredores elétricos e graneleiros avaliza o método de limpeza social que marca a chamada modernização ou avanço das relações capitalistas de produção no país. Por isso, de alto a baixo, produz-se o consentimento diante da expulsão daqueles que, nessa ótica, nem deveriam existir.

A identidade ribeirinha possível ou se constituirá no contraponto, na negação da negação, ou se reduzirá a uma classificação temporária, a uma nova clientela da indústria da miséria. Mais candidatos para arregimentação de regimes de 
trabalho anômalos ou análogos à escravidão. Assim a precarização dos direitos territoriais alimenta a precarização dos direitos sociais como um todo. Desconta-se na natureza dos "menos competitivos" os custos adicionais da última crise financeira. Dessa forma, não pode haver riqueza nova sem devastações prévias de biomas, culturas e saberes.

A supressão objetiva de sujeitos referidos por décadas e séculos a unidades de trabalho familiar polivalentes e cooperativas, estreitamente vinculadas aos ciclos hidrológico e climático, é uma premissa para a invenção dos ribeirinhos como "novos pobres" (ESCOBAR 1998), deslocados do espaço porque deslocados do tempo. Da invisibilidade em que viviam - que paradoxalmente produziu autonomia provinda da multivariada economia da várzea amazôni$\mathrm{ca}$-, alcançaram uma visibilidade hierarquizante e discriminadora.

Essa precarização exemplar reduz ou extingue espaços pactuados de interação social e de reconhecimento, incluindo toda a legislação e normativas protetivas decorrentes desses pactos. $\mathrm{O}$ intento de pôr fim ao padrão geral encerra a busca por qualquer generalização, ou seja, qualquer universalização de benefícios civilizatórios. Um meio digno, real e almejável para todos parece inconciliável com a máxima ostentação da prosperidade, como novo sentido e espírito do capitalismo financeirizado e global, mais ainda nas periferias intermediárias, que precisam replicar desigualdades sociais e regionais em escala ampliada.

O princípio legitimatório do combate às desigualdades, que presidiu o intento redemocratizador após 1985 e que pontificou o ordenamento constitucional de 1988, parece ter se exaurido em 2016. Condições econômicas, referentes ao controle transnacional e financeiro da riqueza, e condições políticas, referentes à dilapidação da força social organizada e ao esvaziamento das instituições representativas, permitiram a emergência de uma agenda ultraliberal para a economia e de uma agenda neofascista de militarização dos territórios e de controle da conduta.

Nesse cenário, os remanescentes de povos tradicionais nos entornos dos grandes empreendimentos da Amazônia só podem existir condicionalmente como "populações vulneráveis" dependentes de medidas assistenciais. 
Seringueiro, castanheiro, pescador, ribeirinho, na narrativa modernizadora hegemônica, deixam de ser concebíveis como categoria não descritiva ou como condição coletiva consciente. Não pode haver alguém que tenha escolhido, aderido, adotado e criado seu território no entremeio dos ciclos econômicos, inventando um ciclo orgânico continuado. O colonialismo reciclado, que emana do modelo rentista-neoextrativista vigente, não admite rastros de usufruto recíproco e equilibrado de bens comuns.

A dinâmica destrutivo-criadora do capitalismo no Brasil é intensiva o suficiente para promover silenciamentos territoriais com poder retroativo. Epistemicídios para que a marcha forçada dos grandes grupos econômicos sobre a Amazônia prossiga sem comoções. Abrem-se temporadas de caça a rentabilidades extraordinárias, abrem-se portos, estações, corridas e corredores para que se prorroguem os efeitos da última crise de sobreacumulação.

A destruição criadora admissível nesse tempo de catástrofes ambientais, sociais e econômicas, se é o caso de ficar nos marcos dessa gramática finalista, seria a interrupção dessas grandes obras e intervenções não recíprocas com o meio, seria a reversão dos grandes fluxos de extração de recursos naturais em grande escala para atender monopólios privados, em detrimento de biomas, solos, rios, vales, dinâmicas climáticas, cidades e mercados locais e regionais.

\section{RIBEIRINHO DO MARAVILHA: CONCEITO E EMPIRIA}

A comunidade Maravilha está situada no município de Porto Velho, no estado de Rondônia, aproximadamente seis quilômetros abaixo do paredão da barragem da UHE Santo Antônio, à margem esquerda do rio Madeira. Passou a ser afetada duramente, como toda área imediatamente à jusante, logo após o fechamento das comportas dessa usina em 2012. Foi um conjunto de desbarrancamentos nas duas margens do rio, quilômetros abaixo, que inviabilizou as barrancas do rio Madeira como área de reprodução econômica, social e cultural das comunidades ribeirinhas, além de condenarem a orla da cidade de Porto Velho, incluindo seu patrimônio histórico. Some-se a isso a intensificação de 
ações de incorporação dessas margens, já desestabilizadas, por empresas que fornecem serviços de transporte e logística hidroviária. Empresas essas vinculadas ao complexo sojeiro que se dedicou nos últimos anos a incrementar seus fluxos exportáveis através do eixo hidroviário Madeira-Amazonas. Além disso, com a construção da ponte sobre o rio Madeira na BR 319 em 2013, a comunidade Maravilha passou a ser engolfada pela dinâmica urbana e periurbana, sofrendo os efeitos da especulação imobiliária, de ocupações clandestinas e do aumento da criminalidade. Os megaempreendimentos e demais obras associadas impuseram reestruturações forçadas na forma como esses sujeitos se relacionavam entre si e como se vinculavam ao meio ambiente.

Antes de passarmos às narrativas desses sujeitos, nos deteremos na categorização "ribeirinho", sobre o que não é e sobre o que é, mas principalmente associar tal denominação ao modo como o comunitário de Maravilha se define e se observa nesse processo. Na abordagem da comunidade Maravilha, optamos pela linha (re)organizativa da identidade étnica, tal como concebida por Fredrik Barth (2000), na contramão de suposições essencialistas vinculadas ou a totalidades socioculturais fechadas ou a determinismos geográficos. Comunidades ribeirinhas - longe de serem definidas por sua localização geográfica ou por algum tipo de encapsulamento temporal - se autodefinem de forma circunstanciada a partir de mobilizações mediante empreendimentos estatais ou privados, com identidades acionadas a partir de "unidades de mobilização" (ALMEIDA, 2006).

Por isso propusemos uma reflexão a partir dessa alteridade sempre recolocada, considerando práticas, processos e vivências singulares. Compreender o processo cosmológico da comunidade em questão é fundamental para que as pluralidades existentes sejam apreensíveis, ressaltando a visão de mundo e de si próprios dos comunitários. O que possibilitou essa leitura foi o contato direto com moradores da comunidade que resistem aos efeitos permanentes gerados pelos grandes empreendimentos no rio Madeira.

A partir de narrativas de representantes das primeiras famílias a se constituírem no local, pudemos identificar um "nós" distinto existindo em meio à trajetória dos acontecimentos aqui levantados: 
"como formou a comunidade, como nasceu a comunidade, a comunidade do Maravilha [...]. É uma comunidade de população tradicional que sempre viveu basicamente da farinha, a fabricação da farinha, né? Do plantio de roças, entendeu? Muitos nativos aqui têm, sempre fizeram roça, né? Desde muito tempo, tendeu? [...] E a outra atividade daqui, dos nativos, é a pesca, né? Extremamente ameaçada agora por causa [...] dos empreendimentos de Santo Antônio e Jirau, né? As usinas, no caso, que aí prejudicou a pesca assim como prejudicou também a cultura de várzea, porque acabaram-se as praias, né? E não tem como plantar na várzea se não tem várzea” (Morador B) ${ }^{6}$.

Percebemos um intento de autoafirmação retroativa, quando postos diante do espelho desfigurador dos grandes empreendimentos. Práticas sociais inviabilizadas se tornam simultaneamente memória e demanda de futuro. Ao passo que a nomenclatura "ribeirinho" ou "tradicional” vai ficando visível, torna-se necessário discutir qual o fôlego dessa "virada identitária".

Comunidades tradicionais somente são entendidas em sua indissociabilidade com seus espaços vividos, os territórios. Diversos empreendimentos interferiram na reprodução físico-cultural-territorial desses povos, desde pavimentações de rodovias até construções de hidrelétricas. Os empreendimentos hidrelétricos atuaram de forma incisiva na conduta desses ribeirinhos. Ao ouvir representantes familiares (reputados dessa forma pelas famílias), notamos que há uma luta simbólica já conflagrada pelo direito de existir singularmente em cenário de negação das possibilidades de viver na barranca do rio Madeira. Possibilidade de plantar, de cultivar em sua várzea rarefeita, de pescar o peixe para comer e o peixe para vender, de trafegar com sua canoa, de traçar e retraçar laços parentais e de afeto. Relatos, como este que segue, realçam tais constatações.

"Desde o tempo da enchente eu tinha muita planta, gente, eu tinha muita coisa. Tinha banana, cupuaçu, mamão, biribá, tudo quanto era de planta, abacate, tudo eu tinha. A água levou tudo que era meu;

\footnotetext{
6 É necessário destacar que todas as referências a nomes dos entrevistados são substituídas por letras do alfabeto, escolhidas aleatoriamente. Tal procedimento foi utilizado com vistas a resguardar sua identidade, considerando as ações e pretensões higienistas da Defesa Civil do Estado de Rondônia e do Município de Porto Velho.
} 
que era meu não, de todos aqui. Além de tudo, eu perdi minhas plantas, mas eu perdi também meu marido, perdi minhas plantas e perdi meu marido. Que eu prefiro que fosse tudo, mas não o meu marido, porque ele era meu amigo, era meu companheiro, nós trabalhava junto e assim nós sobrevivia. Nós tirava nosso sustento daí, levava pra nossa casa, pros nossos filhos [...]. Eu ainda faço um pouco de farinha, duas latas, uma lata, divido pros meus filhos, com os vizinhos que precisam também. Só que fica difícil pra gente, ir lá em Porto Velho e vim... por causa do transporte que nós não tem. [...] a água acabou também. [...] Quem vai fazer uma coisa por nós? Ninguém" (Morador Y).

\section{COMO SER RIBEIRINHO EM UM RIO MECANIZADO}

As narrativas revelam a sensação de impotência e humilhação de moradores que passaram anos sendo completamente ignorados por aqueles que mudaram drasticamente suas condições de vida: as empresas concessionárias e o poder público. Percepção de orfandade que se fez sentir ainda mais forte após a fragilização das bases agroextrativistas dessas comunidades após a instalação das UHE no rio Madeira.

Consideramos, ademais, com base nos depoimentos, determinada morfologia ou estratigrafia da comunidade Maravilha, a partir das propriedades ou posses que se perfilam em corredores, em média de 2,5 km de comprimento por $1 \mathrm{~km}$ de extensão, ao longo do rio Madeira. Existe a referência à terra e a sua posse específica, mas o território referido nas falas se aviva nas práticas sociais comunitárias, nas temporadas e roteiros de pesca, nas coletas de açaí, castanha, pupunha, tucumã e frutas como cupuaçu e biribá. A vinculação com o território seria, nesse sentido, cosmográfica, uma vez que "inclui seu regime de propriedade, os vínculos afetivos que mantém com seu território específico, a história da sua ocupação guardada na memória coletiva, o uso social que dá ao território e as formas de defesa dele" (LITTLE, 2002, p. 4). Tais elementos se destacam no relato que segue: 
"No Maravilha tem muita coisa boa, pô. Tem altas mangas maravilhosas, a cultura de vazea é perfeita, quando a gente consegue plantar, tem feijão de primeira, né? Tem quiabo de primeira, o biribá que é maravilhoso, tucumã... nem eu acho que Rondônia inteiro, ninguém consegue exportar tucumã que nem aqui, essa região do Maravilha. Tem muito tucumanzero, então... são fontes de renda que não são exploradas, pois são poucas conhecidas [...]. A gente não vende porque a gente não tem um comércio aberto pra isso. Então [...] a gente tem múltiplo tipo de riqueza, a gente tem que conseguir botar essa riqueza pra fora; tanta a riqueza cultural [...] quem sabe tecer uma tarrafa hoje? Ninguém, eu não sei, eu não vou mentir não, eu não sei, entendeu?" (Morador Z).

O olhar que temos e os laços que firmamos são construções sociais e simbólicas que vão se estruturando e compondo nossa visão de mundo. Os processos não são homogêneos, e as formas de olhar sobre o que seja "bom para viver" são claramente díspares e heterogêneas. Percebemos que as memórias dos moradores resultam de inúmeras vivências e práticas reiteradas que se davam nos momentos de preparo da mandioca ("farinhada") e das coletas conjuntas de açaí, biribá, tucumã, pupunha e castanha-do-pará (atividades estas realizadas em distintos calendários). Nota-se que essa comunidade, antes desses últimos ciclos de modernização compulsória, se coadunariam perfeitamente com a acepção de "sociedades de afluência” (SAHLINS, 1972).

O ribeirinho, antes potencialmente um titular de direitos, é convertido no pós-desastre das hidrelétricas em flagelado a mercê de políticas emergenciais e assistenciais, quando muito. Maneira cômoda para os causadores e beneficiados de última instância de apagar os rastros de crimes sociais e ambientais. Entram em cena a Defesa Civil e a Polícia Ambiental com suas medidas evacuatórias aplicadas em nome da segurança das pessoas e do meio ambiente sem pessoas.

A forma de lidar com comunidades submetidas a transições forçadas, sem qualquer tipo de diálogo e sem reconhecimento de direitos, é recolocar a memória do vivido como plataforma mínima de diálogo e reconhecimento. Não desistir dos vínculos é ponto de partida para posteriores autodefinições, sempre dinâmicas, articulando-se com as novas necessidades aportadas e com 
escolhas aproximativas acerca do que mais convenha à maioria da comunidade. Na comunidade Maravilha, esse ensaio de reinvenção se faz presente:

\begin{abstract}
"Beraderos que nem esses, [...] é essa força de continuar lutando que elas não vão sair dali, [...], entendeu? [...] rapaz, nós tamos lá, o barranco acabou. A casa dele tá bem e o 'não vamos desistir' é que tá motivando essa galera toda tá aqui, entendeu? Ali e a beira do rio tá aqui, oh. Nós não vamos desistir, então é esse o contexto" (Morador B).
\end{abstract}

A partir do exposto, percebemos que o termo "beradeiro" foi atribuído a partir da necessidade de luta que os moradores tomaram para si em processos que antes lhes pareciam exteriores, em disputa aberta para manter suas referências e suas construções simbólicas. Essa reconstituição de si enquanto parte de uma comunidade se tornou mais evidente após a grande cheia de 2014, em que várias famílias perderam suas casas, plantas, fruteiras, mirantes e portos de atracação de suas canoas. Podemos identificar que esses roteiros de cisão e de recomposição da realidade serviram para fortalecer a relação dos moradores com o lugar e o tempo socializados em um território. Little (2002) ressalta a importância de regimes comuns de convivência e trabalho na constituição identitária dos grupos. Isso fica claro ao pensarmos na categoria ribeirinha. Essa "nomeação", a princípio, se dá de "fora para dentro", ou seja, o termo ribeirinho se fortalece com a chegada dos empreendimentos hidrelétricos e com a circulação de novas formas organizativas e políticas. Da perspectiva das comunidades tradicionais que viveram e vivem ao longo do rio Madeira, conforme se pôde observar nos depoimentos obtidos e em registros anteriores (KLEPPA; GARZON NOVOA, 2017; SILVA; ALVES FILHO, 2002), a autodesignação principia como "beradeiros".

Percebemos que o ímpeto de luta pelo território se tornou inerente à vida dos que ali permanecem. Não comparecem de forma explícita pautas ou bandeiras dos movimentos sociais, mas também não existe conformismo; ao contrário, os moradores de Maravilha expressam uma identificação muito forte com seu território e não consideram deixar suas moradias e vidas. Na prática observamos que está em curso um processo de ressemantização da etnicidade 
(ARRUTI, 2003), em meio aos efeitos desestruturadores dos grandes projetos, as definições e autodefinições são recolocadas e reinventadas, conforme podemos observar a seguir:

"Fazer muitas coisas, só que o que tá faltando é a valorização do conhecimento, dos saberes tradicionais populares, entendeu? Como e de que forma a gente pode valorizar esses saberes? Juntando a parte acadêmica, os saberes científicos de forma que valorize esses saberes culturais, né? Que são os patrimônios históricos de cada comunidade. Eu acho que assim, essa é uma forma a princípio bem básica, né? Tentando fortalecer esses segmentos da comunidade, né? [...] modos de vida pra que esses povos se mantenham aqui, o seu jeito de viver através das sementes, porque eles têm muitas sementes em abundância, entendeu? Tem sementes em abundância aqui. O que precisa, agora, pra comunidade são formas científicas de se manterem aqui, então o povo acadêmico, a comunidade científica, acho que, se buscar, vai conseguir formas de valorizar esses saberes, entendeu?" (Morador L).

Os remanescentes pós-hidrelétricas atestam sua condição de estrangeiros em seu próprio país, párias sociais, sem lugar na cadeia evolutiva do "progresso", verdadeiros refugiados do desenvolvimento. A lógica da despossessão, que marca os megaprojetos, retira o que antes proporcionava autonomia e multiplica vetores de dependência que acentuam a despossessão inicial. Sem navegabilidade segura para pequenas embarcações, estradas são demandadas para a circulação e, dessa forma, difunde-se o desmatamento, o parcelamento irregular de lotes e demais dinâmicas centrífugas típicas da periurbanização nas cidades amazônicas.

Apesar da violência e celeridade das agendas verticais impostas pelos grandes negócios na Amazônia, as comunidades tradicionais não cessam de representar o mundo ao seu modo, buscando reconstruir suas memórias no presente-futuro por meio de suas novas apostas e lutas por reconhecimento. Enquanto o rio Madeira vai sendo incorporado por ciclos econômicos exógenos, tramas clandestinas vão sendo refeitas. A difícil (r)existência (PORTOGONÇALVES, 2004) se coloca não somente no esforço da reconstrução 
material de fontes de renda, mas também na reconstrução cognitiva e afetiva, no sentido da reapropriação social de futuros possíveis.

\section{REFERÊNCIAS BIBLIOGRÁFICAS}

1. ALMEIDA, Alfredo Wagner Berno de. Terras de quilombo, terras indígenas, "babaçuais livres", "castanhais do povo", faxinais e fundos de pasto: terras tradicionalmente ocupadas. Manaus: PPGSCA-Ufam, 2006.

2. ARRUTI, José Maurício. O quilombo conceitual: para uma sociologia do Artigo 68. In: IPEA. Projeto egbé: territórios negros (Koinomia). Brasília, DF, 2003. (Coleção Textos Para Discussão).

3. BARBOT, Janine. Conduzir uma entrevista de face a face. In: PAUGAM, Serge (org.). A pesquisa sociológica. Rio de Janeiro: Vozes, , 2015, p. 102-123.

4. 4. BARTH, Fredrik. O guru, o iniciador e outras variações antropológicas. Rio de Janeiro: Contra Capa, 2000.

5. CARVALHO, Alba Maria Pinho; MILANEZ, Bruno; GUERRA, Eliana. Rentismoneoextrativismo: a inserção dependente do Brasil nos percursos do capitalismo mundializado (1990-2017). In: RIGOTTO, Raquel Maria; AGUIAR, Ada Cristina Pontes; RIBEIRO, Lívia Alves Dias (org.). Tramas para a justiça ambiental: diálogo de saberes e práxis emancipatórias. Fortaleza: Edições UFC, 2018. p. 19-57.

6. ESCOBAR, Arturo. La invención del Tercer Mundo: construcción y deconstrucción del desarrollo. Bogotá: Grupo Editorial Norma, 1998.

7. GEERTZ, Clifford. O saber local: novos ensaios em antropologia interpretativa. Petrópolis: Vozes, 1997.

8. GIDDENS, Anthony. As consequências da modernidade. São Paulo: Editora Unesp, 1991.

9. KLEPPA, Lou-Ann; GARZON NOVOA, Luis Fernando. Comunidades ribeirinhas deslocadas e realocadas: resgatando o patrimônio socioambiental do rio Madeira. Revista Aluá, Porto Velho, n. 1, p. 100-109, 2017.

10. LITTLE, Paul. Territórios sociais e povos tradicionais no Brasil: por uma antropologia da territorialidade. Brasília: UnB, 2002.

11. NOVOA GARZON, Luis Fernando. O licenciamento automático dos grandes projetos de infraestrutura no Brasil: o caso da usinas no rio Madeira. Universidade e Sociedade, Brasília, DF, v. 12, p. 12-34, 2008. 
12. NOVOA GARZON, Luis Fernando. Financiamento público ao desenvolvimento: enclave político e enclaves econômicos. In: ALMEIDA, Alfredo Wagner de et al. Capitalismo globalizado e recursos naturais. Rio de Janeiro: Lamparina, 2010. p. 71-100.

13. NOVOA GARZON, Luis Fernando. Grandes projetos de infraestrutura de "segunda geração" e a expansão da fronteira elétrica na Amazônia. In: HERRERA, José Antônio; CAVALVANTE, Maria Madalena Aguiar. Hidrelétricas na Amazônia: implicações territoriais nas áreas de influência das Usinas nos rios Xingu (Pará) e Madeira (Rondônia). Belém: Gapta, 2017. p. 11-40.

14. OLIVEIRA, Francisco; REICHSTUL, Henri Phillipe. Mudanças na divisão interregional do trabalho no Brasil. Novos Estudos Cebrap, São Paulo, v. 4, p. 131-168, 1973.

15. OSÓRIO, Jaime. Padrão de reprodução do capital: uma proposta teórica. In: FERREIRA, Carla; OSÓRIO, Jaime; LUCE, Mathias (org.). Padrão de reprodução do capital. São Paulo: Boitempo, 2012. p. 37-86.

16. PACHECO, João. Segurança nas fronteiras e o novo indigenismo: formas e linhagens do Projeto Calha Norte. In: PACHECO, João (ed.). Projeto Calha Norte: militares, índios e fronteiras. Rio de Janeiro: Editora UFRJ, 1990. p. 14-33.

17. PORTO-GONÇALVES, Carlos Walter. Geografia da riqueza, fome e meio ambiente: pequena contribuição crítica ao atual modelo agrário/agrícola de uso dos recursos naturais. In: OLIVEIRA, Ariovaldo; MARQUES, Marta (org.). O campo no século XXI: território de vida, de luta e de construção da justiça social. São Paulo: Paz e Terra, 2004. p. 207-254.

18. PORTO-GONÇALVES, Carlos Walter. Amazônia: encruzilhada civilizatória. Tensões territoriais em curso. La Paz: Cide-UMSA, 2018.

19. SAHLINS, Marshall. Stone age economics. New York: Aldine de Gruyter, 1972.

20. SANTOS, Milton; SILVEIRA, Maria Laura. O Brasil: território e sociedade no início do século XXI. Rio de Janeiro: Record, 2004.

21. SEGATO, Rita Laura. Las nuevas formas de la guerra y el cuerpo de las mujeres. Revista Sociedade e Estado, Brasília, DF, v. 29, n. 2, p. 341-371, 2014.

22. SIGAUD, Lígia. Efeitos sociais de grandes projetos hidrelétricos: as barragens de Sobradinho e Machadinho. Rio de Janeiro: Museu Nacional, 1986.

23. SILVA, Josué da Costa; ALVES FILHO, Theóphilo. O viver ribeirinho. In: SILVA, Josué da Costa (org.). Nos banzeiros do rio: ação interdisciplinar em busca da sustentabilidade em comunidades ribeirinhas da Amazônia. Porto Velho: Edufro, 2002. p. 23-40. 
24. SPIVAK, Gayatri Chakravorty. Pode o subalterno falar? Belo Horizonte: Editora UFMG, 2010.

25. ZHOURI, Andrea; LASCHEFSKI, Klemens; PEREIRA, Doralice Barros. A insustentável leveza da política ambiental. Belo Horizonte: Autêntica, 2014.

26. VAINER, Carlos; ARAÚJO, Frederico Guilherme. Grandes projetos hidrelétricos e desenvolvimento regional. Rio de Janeiro: Cedi, 1992.

27. VAINER, Carlos; VIEIRA, Flávia Braga (ed.). BNDES: grupos econômicos, setor público e sociedade civil. Rio de Janeiro: Garamond, 2017. 